\title{
Research On Auto Wiper Rubber Cutting Machine
}

\author{
Zhexiang Zou, Qian Wang, Wenxiu Lai
}

Beijing Institute Technology of Zhuhai, School of Industrial Automation, Guangdong Zhuhai, 519085

Keywords: automotive wiper rubber; molding mold; rubber brush tablets

\begin{abstract}
Wiper rubber is an important part of car wiper. And mold forming is the key to have the suitable rubber brush mould specification during wiper rubber molding process. Based on the rubber molding technology and the GRS-750 rubber-cutting machine's cutting requirements. Focused on the GRS-750 car wiper rubber cutting machine optimization of size and functional structure, to solve the GRS-750-type rubber cutting machine production and health problems. So that the production is more suitable for mold forming products, improved mold production efficiency, reduced production costs and increased the company's production efficiency.
\end{abstract}

\section{Introduction}

GSR-750 car wiper rubber cutting machine was a machine through the machine's different width to determine length parameter before rubber molding. The width of the rubber before molding is determined by the cutting width of the cutter. Through the GRS-750 cutting machine dimensions and functional structure to transform. Increased the film thickness of thickness automatic feedback control machine after optimizing the structure. Then direct connected to the optimized cutting machine to slit and cut through the uniform width of the film without a roll cutting machine ${ }^{[3]}$. Mainly introduce the optimized cutting machine cutting control system. Improve the cutting accuracy, so that the molding specifications more suitable for mold production.

\section{Cutting process of rubber cutter for traditional GRS-750 car wiper}

GRS-750 car wiper rubber cutting machine consists of motor, servomotor, crank - connecting rod mechanism, cutter and feed roller. It controlled feed roller through the servo motor, motor plus crank connecting rod control cutter to achieve cutting rubber ${ }^{[1,2]}$. Traditional rubber cutting process abbreviated as follows:

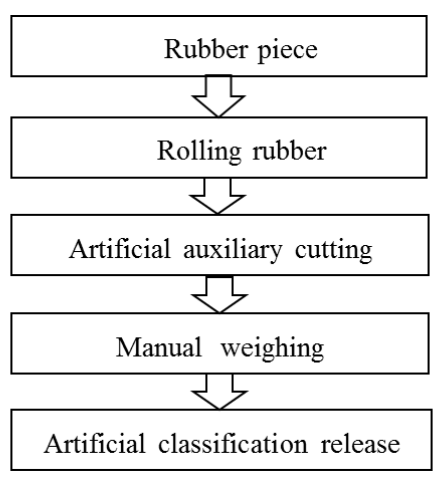

Fig. 1 The process of conventional rubber cutting

GRS-750 car wiper rubber cutting machine must go through a machine out of the film when cutting rubber. In a machine-chip stage by manual detection of hand-held detection of thickness, compared the corresponding standard form. And then according to the difference adjusted repeatedly until the required range. The thickness of the rubber sheet depended on the experience to determine that there was a greater risk of thickness changes. Thickness changes on the cutting weight of the cutting machine had a greater impact on the cutting weight ${ }^{[4]}$. This cutting process was too complex, wasted a lot of labor, low cutting accuracy and occupied a larger workspace.

\section{Optimization of rubber cutter for automobile}

\subsection{Specific problem's optimization}

In order to reduce the cutting complicated processes, save labor, improve cutting accuracy and production efficiency. According to the old cutting machine evaluation to study the shortcomings and improve the design. Including:

(1) Need to store material and use materials

(2) Cutting model is not easy to change

(3) Cutting requires a weighing station 


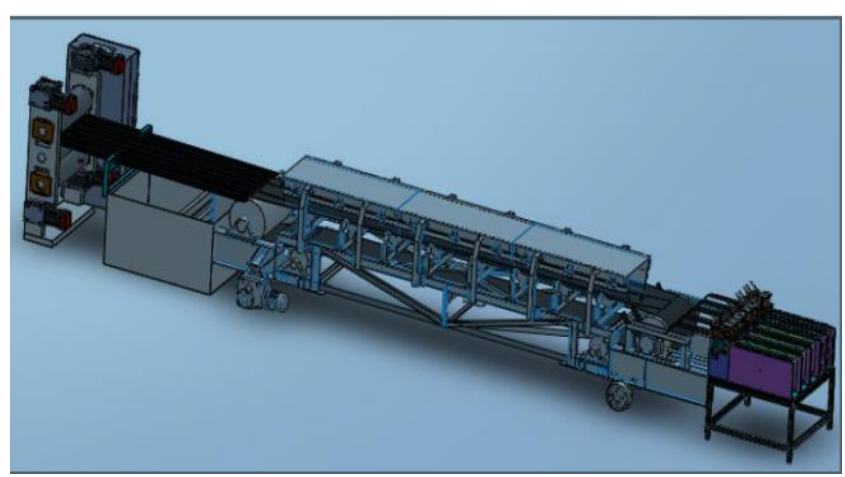

Fig .2 New type of car wiper rubber cutting machine

Understood the old cutting machine's shortage, used a cutting way which took a new cutting method directly attached to the production line. And omitted the middle of the material storage links that improved the middle of the material problems and reduced staff costs.

\subsection{Optimization scheme:}

(1) Improved the specification adjustment method of film. The new car wiper rubber cutting machine cutting rotated 90 degrees than before. This provided only a fixed cutting width. By cutting the cutting set to adjust the parameters between the different sizes of the switch ${ }^{[6,]}$. Figure 3 and figure 4 the change of improved cutting machine's cutting way.

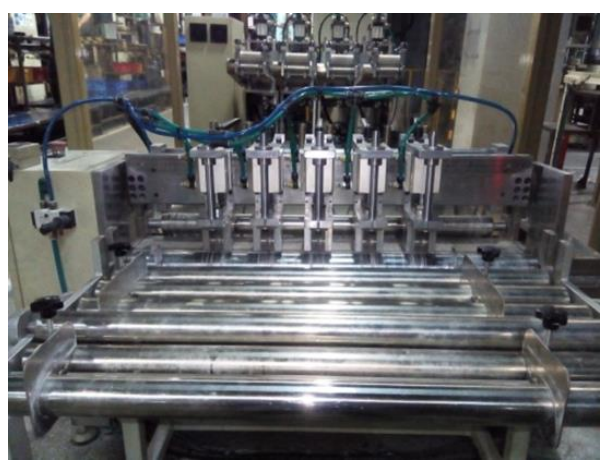

Fig .3 Rubber points of the machine

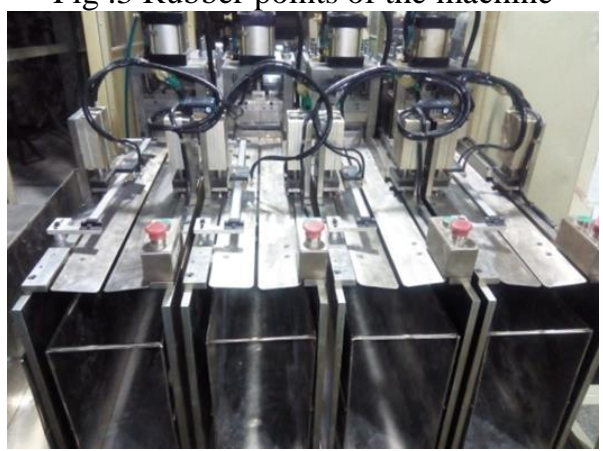

Fig .4 Rubber cutting machine

( 2 ) Cutting control system mainly consists of programmable logic controller (PLC), control module, variable frequency drive speed module and servo motor drive module components ${ }^{[5]}$. A grating sensing device cuts the length of the rubber. Increase the thickness of the automatic feedback device to control the film out of a machine thickness. Achieve the thickness of automatic control module to improve the cutting accuracy ${ }^{[11,12]}$

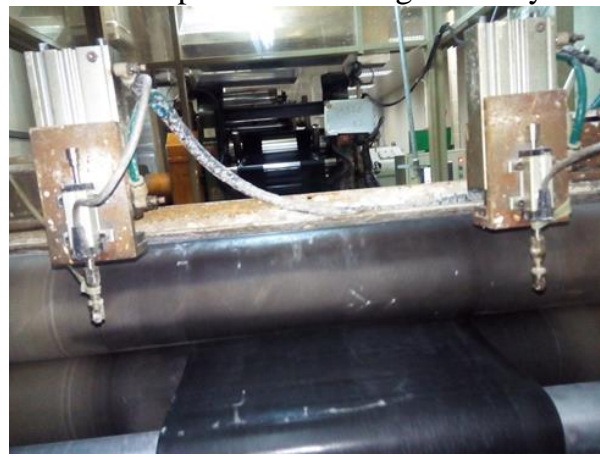

Fig .5 Thickness detection of the feedback control device

From the improved process flow chart can be seen that the new cutting machine reduced three processes which is the middle volume process, brushed weighing and weight classification than the GRS-750 car wiper rubber cutting machine $^{[10]}$.

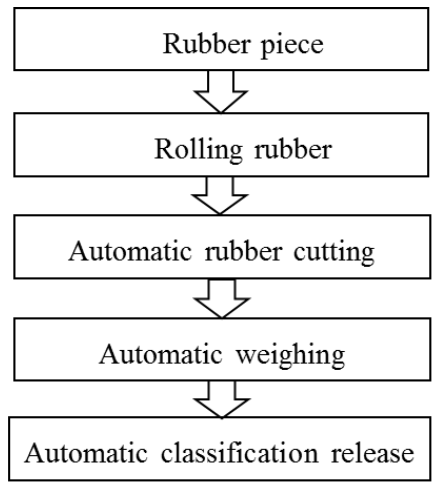

Fig. 6 Optimization of rubber cutting process

\subsection{Cutter design improvement}

(1)The old cutting tool has only one fixed point. For the new cutter, two fixed points must be used to limit the lift position of the cutter. Two fixed points are designed with one hoistway and the other with a locating spool. In the positioning of the role of the sliding column, the cutter in the lift slot was more stable ${ }^{[6]}$.

(2) Because the cutter assembly is a gap fit, so the shaft and cutter, shaft and fixed parts are used with clearance ${ }^{[13]}$. Cutting the rubber caused wear and tear on the tool under the pressure of the cylinder. Wear lead to cutting blades and rollers with the inner hole of wear and tear, caused the whole piece of cutting blades rotating uneven and the whole cutting process was unstable. So the same is a clearance fit but increased the four positioning bolt. The blade with cutter shaft turn that reduced tool wear. In addition, in the middle of the fixed piece with the axis of rotation increased bearing and reduced the inhomogeneous of rotating friction. Through the above two improvements can improve the stability of the cutting process.

(3) Adopted the blade material hardness larger than roller hardness. This improved the cutter wear problems and improved the service life of the cutter wearing parts.

After these three points of improvement, the stability of the cutting knife had a big part of ascension. The new cutting 
tool is shown in Figure 7.

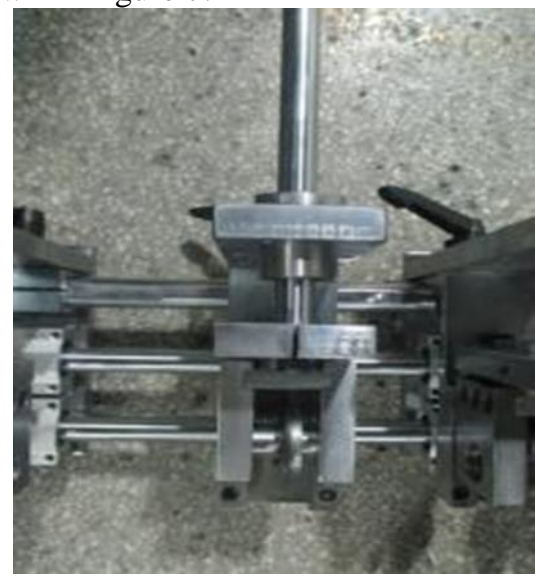

Fig.7 Structure of cutter

\subsection{Improved cutting brush length}

New type of car wiper rubber cutting machine is another factor affecting the effects of cutting length in the debugging process. Cutting length was calculated by the servo motor drum circumference. This calculation is not a problem for a single cutting machine basically.

This design used four cutting machine cutting together to improve cutting efficiency. The four cutters control panel set the same parameters but the cut length varies. Because the diameters of the four tools feed rollers are different. In addition, the four-tool feed roller pressure regulation cannot be unified. This led to products with cutting machine cutting different length. The deviation will increase with the increase of the length of the product. From the horizontal data analysis can be obtained that different cutting machine for cutting the length of the same products have different cutting length ${ }^{[7]}$.

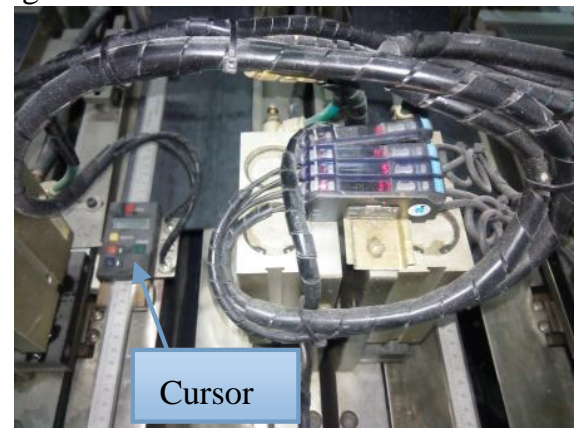

Fig. 8 The position of the cursor scale

Solution 1: Increased the amount of compensation in the PLC program. This compensation, however, requires compensation both horizontally and vertically, which complicates the entire control panel, making the function of the machine inoperable to simplify the production process. What's more, this operation delayed the production cycle and reduced production efficiency. The solution feasibility analysis due to the complicated operation and affected the efficiency that was denied in the company.

Solution 2: Regardless of the process just results that change the length of the control device. Removed the roller diameter size and roller pressure differ the root cause, use scale light induction cutting products. So as long as the four-beam ruler position in a straight line, you can ensure that four different cutting machine cutting bias. In addition, cutting the first product checked the parameters. If you set and cut parameters, you will have to adjust the position of the light gauge to ensure that the cutting product is in use. This feedback production can reduce the product changes caused by different length of the tool. Improved data. Improved the effect: From the above table data can be drawn. Improved for light gauge light induced after cutting products. From longitudinal data analysis can be obtained with the cutting machine can produce products with different length of the deviation of value wouldn't increase with the increase of the length of the product. From the horizontal data analysis can be drawn different cutting machine cutting the same length of the product had the same cutting length.

\begin{tabular}{ccccc}
\hline $\begin{array}{c}\text { Set length } \\
(\mathrm{mm})\end{array}$ & $\begin{array}{c}\text { Cutting length of } \\
\text { No.1 machine } \\
(\mathrm{mm})\end{array}$ & $\begin{array}{c}\text { Cutting length of } \\
\text { No.2 machine } \\
(\mathrm{mm})\end{array}$ & $\begin{array}{c}\text { Cutting length of } \\
\text { No.3 machine } \\
(\mathrm{mm})\end{array}$ & $\begin{array}{c}\text { Cutting length of } \\
\text { No.4 machine } \\
(\mathrm{mm})\end{array}$ \\
\hline 300 & 300 & 301 & 300 & 300 \\
400 & 400 & 400 & 400 & 401 \\
500 & 500 & 501 & 500 & 500 \\
600 & 600 & 600 & 601 & 600 \\
700 & 700 & 700 & 700 & 700 \\
\hline
\end{tabular}

Table I Improved cut data sheet

\section{Determination of the ability of the cutting machine}

The structure and function of the GRS-750 rubber-cutting machine are optimized. Using the grating sensing device to cut rubber length, increase the thickness of the automatic feedback device. Control the slice thickness, realize the thickness automatic control module, and improve the cutting precision. Reducing the cutting process can be part of the removal process, to further enhance the cutting efficiency of the cutting machine.

\begin{tabular}{cccccc}
\hline Machine & S/N & $\begin{array}{c}\text { Cutting } \\
\text { Number } \\
\text { (piece) }\end{array}$ & $\begin{array}{c}\text { Cutting } \\
\text { Time } \\
\text { (s) }\end{array}$ & $\begin{array}{c}\text { Cutting } \\
\text { Efficiency } \\
\text { (piece } \backslash \text { s) }\end{array}$ & Remark \\
\hline New Car & 1 & 1000 & 1080 & 0.925926 & \\
Wiper & 2 & 2000 & 2160 & 0.925926 & \\
Rubber & 3 & 3000 & 3240 & 0.925926 & \\
Cutting & 4 & 4000 & 4320 & 0.925926 & Efficiency \\
Machine & 5 & 5000 & 5400 & 0.925926 & increased \\
GRS-750 & 1 & 1000 & 1440 & 0.694444 & about \\
CarWiper & 2 & 2000 & 2880 & 0.694444 & $10 \%$. \\
Rubber & 3 & 3000 & 4320 & 0.694444 & \\
Cutting & 4 & 4000 & 5760 & 0.694444 & \\
Machine & 5 & 5000 & 7200 & 0.694444 & \\
\hline
\end{tabular}

Table II The operation of the cutting machine

Redesigned and improved the GRS-750 car wiper rubber cutting machine, tested the stability of the new car wiper rubber cutting machine by using the CMK (machine stability test) software, and used the new car wiper cutting machine to cut and sample. In the normal working conditions of the machine, take 50 samples and measure the 
parameters. After collecting data, obtained machine stability results assessed by editing software. The results are to meet the machine stability. Cutting report the results as shown below:

\begin{tabular}{|c|c|c|}
\hline Distribution Mode & \multicolumn{2}{|r|}{ Normal Distribution } \\
\hline Calculation & \multicolumn{2}{|r|}{$\mathrm{M}_{2}$ Percentage $(0.135 \%-50 \%-99.865 \%)$} \\
\hline Potential Capacity Index & $\mathrm{C}_{\mathrm{M}}$ & $4.05 \leq \mathbf{5 . 0 5} \leq 6.05 \quad 0$ \\
\hline Critical Capabilities Index & $\mathrm{C}_{\mathrm{MK}}$ & $3.99 \leq 4.98 \leq 5.98 \quad 0$ \\
\hline \multicolumn{3}{|c|}{ Fulfil Requirements $\left(\mathrm{C}_{\mathrm{M}}, \mathrm{C}_{\mathrm{MK}}\right)$} \\
\hline \multicolumn{3}{|c|}{ Table III Cutting length CMK report } \\
\hline Distribution Mode & \multicolumn{2}{|r|}{ Normal Distribution } \\
\hline Calculation & \multicolumn{2}{|r|}{$\mathrm{M}_{2}{ }_{2}$ Percentage $(0.135 \%-50 \%-99.865 \%)$} \\
\hline Potential Capacity Index & \multicolumn{2}{|r|}{$1.70 \leq \mathbf{2 . 1 2} \leq 2.54 \quad 0 \quad 1.67$} \\
\hline Critical Capabilities Index & $\mathrm{C}_{\mathrm{MK}}$ & $1.55 \leq 1.95 \leq 2.35 \quad \square$ \\
\hline \multicolumn{3}{|c|}{ Fulfil Requirements $\left(\mathrm{C}_{\mathrm{M}}, \mathrm{C}_{\mathrm{MK}}\right)$} \\
\hline \multicolumn{3}{|c|}{ TableIV Cutting width CMK report } \\
\hline Distribution Mode & \multicolumn{2}{|r|}{ Johnson - Transformation } \\
\hline Calculation & \multicolumn{2}{|r|}{$\mathrm{M}_{2}$ Percentage $(0.135 \%-50 \%-99.865 \%)$} \\
\hline Potential Capacity Index & $\mathrm{C}_{\mathrm{M}}$ & $4.54 \leq \mathbf{5} . \mathbf{6 5} \leq 6.77$ \\
\hline Critical Capabilities Index & $\mathrm{C}_{\mathrm{MK}}$ & $3.20 \leq 4.00 \leq 4.79 \quad 5$ \\
\hline & \multicolumn{2}{|c|}{ Fulfil Requirements $\left(\mathrm{C}_{\mathrm{M}_{i}} \mathrm{C}_{\mathrm{MK}}\right)$} \\
\hline
\end{tabular}

Table V Cutting width CMK report

From the above table, the new car wiper rubber cutting machine CMK machine capacity to meet the requirements of the machine work. $(\mathrm{CMK} \geqslant 1.66)$.

\section{4 . Conclusion}

Through the above research, the improved new car wiper rubber cutting machine compared with original model. The new cutting machine more effective to ensure the mold production demand parameters. At the same time, the new car wiper rubber cutting machine reduced two cutting process and two operating staff than the GRS-750 car wiper rubber cutting machine. Reduced production costs and improved production efficiency significantly.

\section{References}

[1] Zhu Xiaolu. Gear Transmission Design Manual [M]. Beijing: Chemical Industry Press,2005.P144-146.

[2] Qiu Xuanhuai. Mechanical Design [M]. Beijing: Higher Education Press, 1997.P120-125.

[3] Dai Shaodu. Materials Mechanics [M]. Beijing: National Defense Industry Press,2002.P108-115.

[4] Liu Zhairu. Mechanical Drawing [M]. Beijing: Higher Education Press,2001 P89-90.

[5] Ma Youliang. Automobile Electric and Electronic Control System [M]. Beijing: Mechanical Industry Press, 2013: 148.

[6] Cao Qinggong. Automatic Cutting Machine Design [J]. Science and technology information industry technology, 2012: 19-20.

[7] Dan Shanshan. the Design Method of Cutting Machine [M]. Beijing: Mechanical Industry Press, 2001: 18-20.

[8] Lu Yongxing, Dai Sujiang, Dai Xinping. Design of Magnetic Absorption Type Double Wheel Shock Absorption Cutting Machine [J]. Journal of Jinhua Vocational \& Technical College, 2012,12 (7): 15-17.

[9] Luo Da. Design of Beverage Plastic Anti - theft Bottle Cap Cutting Machine Based on Two - step Method [J]. Mechatronics Engineering, 2012,12 (7): 20-22.

[10] Li Zhongsheng. the Mechanical Design Basis [M]. Beijing: Higher Education Press, 2006: 27-28.

[11] Zou Changfu, Li Jinling, Kong Lingjia. Design of Adjustable Cutting Machine [J]. Machine Design \& Manufacture, 2011,32 (9): 44-46.

[12] Jia Yaxiao. Design of Small Precision Metallographic Sample Cutting Machine Based On PLC Technology [J]. Coal Mine Machinery, 2010,32 (7): 17-19.

[13]Liao Nianzhao. Interchangeability and Technical Measurement [M]. Beijing: China Metrology Publishing House, 2000: 54-56.

[14]Tao Jingxuan, Chen Yihua, Song Mingshun, Gu Longfang. Some Thoughts on Process Capability Analysis [J] Bulletin of Science and Technology, volume, 2007,12 (1): 7-8.

[15]Da Shiliang. Discussion on Some Problems in Application of Process Capability Index and Equipment Capability Index [J] Shanghai Quality, volume, 2002,12 (2): 20-22. 